\title{
Height, body mass index, and prostate cancer: a follow-up of 950000 Norwegian men
}

\author{
A Engeland ${ }^{*, 1}, \mathrm{~S}$ Tretli $^{2}$ and T Bjørge ${ }^{3}$ \\ 'Division of Epidemiology, Nonwegian Institute of Public Health, PO Box 4404 Nydalen, N-0403 Oslo, Norway; ${ }^{2}$ The Cancer Registry of Norway, Institute \\ of population-based cancer research, N-0310 Oslo, Nonway; ${ }^{3}$ Department of Pathology, The Norwegian Radium Hospital, N-03 10 Oslo, Norway
}

The present study explored body mass index (BMI), height, and risk of prostate cancer in a large Norwegian cohort of 950000 men aged 20-74 years, whose height and weight were measured in a standardised way in the period 1963-1999. These were followed for an average of 21 years. The Cox proportional hazard models were used in the analyses. During follow-up, 33300 histologically verified cases of prostate cancer were registered. The risk of prostate cancer increased by both BMl and height. The magnitude of the increase by $\mathrm{BMI}$ was modest, the relative risk (RR) of obese men (BMI $\geqslant 30$ ) compared with normal weighted was 1.09 (95\% Cl: I.04-1. I5). However, the RR at age 50-59 years was I.58 (95\% Cl: I.29- I.94) in men being obese at about age 45 years compared with normal weighted men. The tallest men had an RR of $1.72(95 \% \mathrm{Cl}: 1.46-2.04)$ compared with the shortest men. The overall effect of BMI on the incidence of prostate cancer was modest. The larger effect found in men aged 50-59 years might partly explain the previous inconsistent findings.

British Journal of Cancer (2003) 89, 1237-1242. doi:I0.1038/sj.bjc.660 I 206 www.bjcancer.com

(C) 2003 Cancer Research UK

Keywords: prostate cancer; cohort study; Norway

Worldwide, prostate cancer is the third most common malignancy in men with an estimated number of 500000 cases in the year 2000, three-quarters in men aged 65 years or older (Parkin et al, 2001). Around 1990, the incidence of prostate cancer increased in many countries due to the introduction of widespread blood testing with prostate-specific antigen (PSA) (Parkin et al, 2001). In Norway, testing with PSA was introduced at the beginning of the 1990s (Harvei, 1999).

The aetiology of prostate cancer is largely unknown (Hsing et al, 2001). However, hormonal relations, age, and race are known risk factors. The relation between age and the incidence of prostate cancer is especially strong. The large age-gradient, combined with the ageing of many Western populations, will make prostate cancer an increasing health problem.

Certain studies on body mass index (BMI) and prostate cancer risk have concluded that there is no association (Bianchini et al, 2002). In a review of the literature up to 1998 (Bergström et al, 2001), however, it was concluded that elevated BMI was associated with the risk of prostate cancer. Overweight men $(25<\mathrm{BMI}<30$;

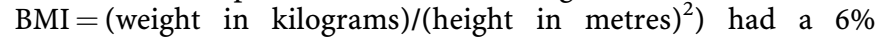
increased risk compared with normal-weighted men (BMI 20$25)$, while obese men $(B M I \geqslant 30)$ had a $12 \%$ increased risk. The proportion of prostate cancer attributable to overweight and obesity in European men was estimated to be $4 \%$ (Bergström et al, 2001). A review of 12 case-control studies and 11 cohort studies (Nomura, 2001), revealed the inconsistencies between studies on this issue. If the relative risks (RRs) found by Bergström et al are close to the 'real' level, the increased risk of prostate cancer

*Correspondence: A Engeland; E-mail: anders.engeland@fhi.no Received 7 April 2003; revised 24 June 2003; accepted 24 June 2003 associated with overweight/obesity is small. Large and wellconducted studies are necessary to reveal increases in the risk of this magnitude.

Also, the findings in studies on the association between height and prostate cancer is inconsistent; two of nine cohort studies found a significant positive association between height and prostate cancer, but none of six case-control studies (Nomura, 2001).

The aim of the present study was to explore the relation between height and BMI and the risk of prostate cancer in a large Norwegian cohort with height and weight measurements in the age $20-74$ years.

\section{MATERIAL AND METHODS}

\section{Study population}

During 1963-1975, height and weight were measured as part of a screening programme aimed at detecting tuberculosis in the general Norwegian population (Waaler, 1984; Bjartveit, 1997). This mass examination was compulsory for persons aged 15 years and older, and enrolled 1.7 million people. The attendance was about $85 \%$ in persons above the age of 15 years (Waaler, 1984). Previous reports have described the impact of adults' height and weight on mortality (Waaler, 1984), and the material has also been utilised to explore relations between BMI and cancer incidence (Helseth and Tretli, 1989; Tretli, 1989; Tretli and Magnus, 1990; Thune et al, 1993; Robsahm and Tretli, 1999; Tretli and Robsahm, 1999). In 1963-1964 and in 1972-1999, height and weight were also measured in health surveys in different parts of Norway (Bjartveit et al, 1979; Bjartveit, 1997). The attendance in the mid-1970s was 
$85-90 \%$, but decreased to about $75 \%$ in the mid-1990s (Bjartveit, 1997). The complete cohort has recently been used in a study of the impact of height and BMI on mortality (Engeland et al, 2003).

The body weight (kilograms) was measured on scales that were calibrated regularly, and registered to the nearest half kilogram. Body height was measured and noted to the nearest centimetre. The height was measured without shoes, and weight was measured with the subject wearing light clothing. If the height and weight measurements were performed under irregular circumstances, the measurement was excluded (the persons were wearing shoes, the persons were disabled, etc.). Further, measurements without registered height or height below $120 \mathrm{~cm}$, or without registered weight or weight below $20 \mathrm{~kg}$ were excluded (67 measurements).

In the present study, the earliest accepted measurement between age 20 and 75 years was used for each man. There were 952142 men with such measurements.

The study cohort was linked to the Death Registry at Statistics Norway to follow all persons in the present study from the date of measurement until eventual emigration or death. A unique 11-digit identification number assigned to all individuals living in Norway after 1960 simplified the linkage.

All cases of prostate cancer (International Classification of Diseases, seventh revision (ICD-7): 177) in the study cohort were identified by linkage to the Cancer Registry of Norway. Cancer registration, covering the entire Norwegian population of about 4.5 million inhabitants (2002), was initiated in 1952, and reporting of all diagnosed cancer cases has since been compulsory by law. Notifications are independently issued by all clinical and pathology departments involved in the diagnosis and treatment of cancer. In addition, all death certificates with a mention of premalignant or malignant disease reach the registry. The quality of the prostate cancer data in the Cancer Registry of Norway has been assessed, finding an error rate of about $1 \%$ of all data elements (Harvei et al, 1996).

In the present study, only histologically verified prostate cancer diagnoses were included. Men with a prostate cancer diagnosis prior to the height and weight measurements were excluded (676 men). The men in the cohort were followed up from the date of measurement until date of prostate cancer diagnosis, emigration, age 100 years, death, or until 30 June 2001. Altogether, 951466 men were eligible for the study. A small number of these (seven men) were lost to follow-up.

\section{Statistical methods}

The Cox proportional hazards regression models (Cox and Oakes, 1984), with time since measurement as time variable, were fitted to obtain RR estimates of prostate cancer for different groups. In the analyses, the following categorised variables were included:

(1) age at measurement: $20-24$ years, .., 65-69 years, and 70-74 years.

(2) year of birth: $<1900,1900-1909, \ldots, 1940-1949$, and $\geqslant 1950$.

(3) BMI ((weight in kilograms)/(height in metres) $)^{2}$ :

(a) detailed categorisation: BMI $<18.50,18.50-19.49, \ldots$, $22.50-23.49,23.50-24.99,25.00-27.49, \ldots, 32.50-34.99$, and $\geqslant 35.00$.

(b) WHO categorisation (World Health Organization Consultation on Obesity, 1998): BMI $<18.50$ (underweight) 18.50-24.99 (normal range), 25.00-29.99 (preobese/overweight), and $\geqslant 30.00$ (obese).

(4) height (cm): $<160,160-169,170-179,180-189$, and $\geqslant 190$.

Tests for linear trend were calculated by including BMI and height, respectively, as continuous variables.

The proportionality assumption in the Cox model was assessed by inspecting log-minus-log plots, results from stratified analyses, and results from separate analyses for different intervals of observation time. To explore whether BMI had a different impact on prostate cancer in the different age groups, analyses stratified on attained age and age at measurement were performed.

All analyses were carried out with the statistical program package SPSS (SPSS Inc., 2001). The results were presented as RRs of prostate cancer with $95 \%$ confidence intervals (CI).

\section{RESULTS}

A total of 951459 men (mean age: 44.5 years) were followed for an average of 21.0 years (range $0-38$ years), comprising 20010705 person-years (Table 1). Among these, a total of 33314 prostate cancer diagnoses were observed. The mean age at diagnosis was 73 years and the overall mean BMI was $24.9 \mathrm{~kg} \mathrm{~m}^{-2}$.

In men with BMI below $35.0 \mathrm{~kg} \mathrm{~m}^{-2}$, the risk of prostate cancer was increasing with increasing BMI (Table 2), from an RR of 0.92

Table I Number of observed prostate cancer cases, person-years, and overall prostate cancer rates

\begin{tabular}{|c|c|c|c|}
\hline Variable & Prostate cancer & Person-years & Cancer rate $^{a}$ \\
\hline \multicolumn{4}{|c|}{ Age at measurement } \\
\hline $20-24$ & 158 & 2242795 & 7 \\
\hline $25-29$ & 464 & 2255138 & 21 \\
\hline $30-34$ & 1054 & 2064155 & 51 \\
\hline $35-39$ & 2142 & 2233231 & 96 \\
\hline $40-44$ & 3798 & 3471729 & 109 \\
\hline $45-49$ & 5198 & 2411995 & 216 \\
\hline $50-54$ & 5539 & 1881942 & 294 \\
\hline $55-59$ & 5470 & 448056 & 378 \\
\hline $60-64$ & 4432 & | 00995 | & 439 \\
\hline $65-69$ & 3162 & 642324 & 492 \\
\hline $70-74$ & 1897 & 349388 & 543 \\
\hline \multicolumn{4}{|l|}{ Year of birth } \\
\hline$<1900$ & 2200 & 457438 & 481 \\
\hline $1900-1909$ & 7666 & | 733605 & 442 \\
\hline $1910-1919$ & 11117 & 3390484 & 328 \\
\hline $1920-1929$ & 8617 & 4723760 & 182 \\
\hline $1930-1939$ & 3071 & 4035564 & 76 \\
\hline $1940-1949$ & 611 & 4250296 & 14 \\
\hline$\geqslant 1950$ & 32 & 1 419558 & 2 \\
\hline \multicolumn{4}{|l|}{ Attained age } \\
\hline $20-29$ & 0 & 765591 & 0 \\
\hline $30-39$ & 3 & 2231577 & 0 \\
\hline $40-49$ & 126 & 4670388 & 3 \\
\hline $50-59$ & 1813 & 4752559 & 38 \\
\hline $60-69$ & 9511 & 4178645 & 228 \\
\hline $70-79$ & 15429 & 2645662 & 583 \\
\hline $80-99$ & 6432 & 766283 & 839 \\
\hline \multicolumn{4}{|l|}{$\mathrm{BMI}\left(\mathrm{kg} \mathrm{m}^{-2}\right)$} \\
\hline$<18.50$ & 147 & 130103 & 113 \\
\hline $18.50-19.49$ & 367 & 335470 & 109 \\
\hline $19.50-20.49$ & 914 & 790346 & 116 \\
\hline $20.50-21.49$ & 1778 & | 474 |33 & 121 \\
\hline $21.50-22.49$ & 2912 & 2215710 & 131 \\
\hline $22.50-23.49$ & 3766 & 2630649 & 143 \\
\hline $23.50-24.99$ & 6983 & 4248713 & 164 \\
\hline $25.00-27.49$ & 10001 & $5|5690|$ & 194 \\
\hline $27.50-29.99$ & 4523 & $210797 \mid$ & 215 \\
\hline $30.00-32.49$ & 1453 & 672027 & 216 \\
\hline $32.50-34.99$ & 370 & 176482 & 210 \\
\hline$\geqslant 35.00$ & 100 & 72201 & 139 \\
\hline \multicolumn{4}{|l|}{ Height $(\mathrm{cm})$} \\
\hline$<160$ & 245 & 138073 & 177 \\
\hline $160-169$ & 7091 & 3153938 & 225 \\
\hline $170-179$ & 19247 & 10958081 & 176 \\
\hline $180-189$ & 6421 & 5367993 & 120 \\
\hline$\geqslant 190$ & 310 & 392620 & 79 \\
\hline Total & 33314 & 20010705 & 166 \\
\hline
\end{tabular}

a Number of prostate cancer cases per 100000 person-years. 
Table 2 Relative risk (RR) of prostate cancer with 95\% confidence intervals $(\mathrm{Cl})$ from Cox regression analysis; age at measurement and birth cohort were included in the model in addition to either one of the categorisations of body mass index (BMI) or height

\begin{tabular}{lrrrr}
\hline Variable & Cancer cases & RR & $\mathbf{9 5 \% ~ C l}$ & $\begin{array}{c}\text { Test for } \\
\text { linear trend }\end{array}$ \\
\hline $\mathrm{BMI}\left(\mathrm{kg} \mathrm{m}^{-2}\right)$ & & & & \\
$<18.50$ & 147 & 0.92 & $0.78-1.08$ & \\
$18.50-24.99$ & 16720 & 1.00 & Referent & \\
$25.00-29.99$ & 14524 & 1.07 & $1.05-1.09$ & \\
$\geqslant 30.00$ & 1923 & 1.09 & $1.04-1.15$ & \\
$\mathrm{BMI}\left(\mathrm{kg} \mathrm{m}^{-2}\right)$ & & & & \\
$<18.50$ & 147 & 0.92 & $0.78-1.08$ & \\
$18.50-19.49$ & 367 & 0.91 & $0.81-1.01$ & \\
$19.50-20.49$ & 914 & 0.95 & $0.88-1.02$ & \\
$20.50-21.49$ & 1778 & 0.94 & $0.89-1.00$ & \\
$21.50-22.49$ & 2912 & 0.97 & $0.93-1.02$ & \\
$22.50-23.49$ & 3766 & 1.00 & Referent & \\
$23.50-24.99$ & 6983 & 1.04 & $1.00-1.09$ & \\
$25.00-27.49$ & 10001 & 1.07 & $1.03-1.11$ & \\
$27.50-29.99$ & 4523 & 1.07 & $1.02-1.12$ & \\
$30.00-32.49$ & 1453 & 1.09 & $1.03-1.16$ & \\
$32.50-34.99$ & 370 & 1.15 & $1.03-1.28$ & \\
$\geqslant 35.00$ & 100 & 0.93 & $0.76-1.13$ & $P<0.001$ \\
Height $(\mathrm{cm})$ & & & & \\
$<160$ & 245 & 0.64 & $0.57-0.73$ & \\
$160-169$ & 7091 & 0.89 & $0.87-0.92$ & \\
$170-179$ & 19247 & 1.00 & Referent & \\
$180-189$ & 6421 & 1.06 & $1.03-1.09$ & \\
$\geqslant 190$ & 310 & 1.11 & $0.99-1.24$ & $P<0.001$ \\
\hline
\end{tabular}

${ }^{\mathrm{a}} \mathrm{BMI}$ and height, respectively, were included as continuous variables.

in men with BMI below $18.5 \mathrm{~kg} \mathrm{~m}^{-2}$ to 1.15 in men with BMI $32.5-34.9 \mathrm{~kg} \mathrm{~m}^{-2}$ compared with men with BMI $22.5-23.4 \mathrm{~kg} \mathrm{~m}^{-2}$ (reference group). An analysis stratified by age at measurement revealed that the excess risk of prostate cancer in obese men was roughly of similar magnitude irrespective of age at measurement (Table 3). However, an indication of higher obesity-associated risk was seen in those being youngest at measurement. Men measured at the age of 20-29 years were younger than 70 years at the end of follow-up. In the analyses stratified by attained age (Table 4), the RR of prostate cancer in age 50-59 years for obese men (measured at an average age of 45 years) was 1.58 (95\% CI: $1.29-1.94$ ) compared with men with BMI within the 'normal range'.
An increasing risk of prostate cancer with increasing height was observed (Table 2). The tallest men had an RR of 1.72 (95\% CI: 1.46-2.04) compared with the shortest men. The mean height was increasing with increasing birth year from $170 \mathrm{~cm}$ for men born around 1890 to $180 \mathrm{~cm}$ in those born around 1975 (mean annual increase: $0.12 \mathrm{~cm}$ ). However, including men born before 1930 gave almost identical results with regard to the impact of both BMI and height on the risk of prostate cancer.

In order to reduce the potential effect of persisting disease at the weight measurement, analyses were performed with exclusion of the first 5 years of follow-up. This exclusion did not change the results. Since PSA testing was introduced around 1990, leading to an increase in the registered incidence of prostate cancer in Norway, analyses were performed using 31 December 1989 as the final date for the end of follow-up. Similar results were obtained.

Use of age-specific quintiles of height, weight, and BMI instead of the categorisation used above showed monotonely increasing risk of prostate cancer by increasing quintile. Compared with the lowest quintile, the highest quintile of height, weight, and BMI had RRs of 1.20 (95\% CI: $1.16-1.25), 1.22$ (95\% CI: $1.18-1.26)$, and 1.13 (95\% CI: $1.09-1.17)$, respectively.

\section{DISCUSSION}

In the present study, height and weight were measured in 950000 men, and these men were successively followed for an average of 21 years with respect to incidence of prostate cancer. An increasing risk of prostate cancer was observed both with increasing BMI and height.

Our study subjects were recruited from population-based studies with high attendance, and the measurements were performed in a standardised way. Use of a unique identification number and population-based registries on deaths, emigrations, and cancer incidence ascertained an almost complete follow-up of the study subjects (951 466 men). Only seven men were lost to follow-up. By the end of follow-up, $58.3 \%$ of the men were alive without a diagnosis of prostate cancer $(0.9 \%$ of these had emigrated from Norway), 38.2\% were dead, and 3.5\% had a diagnosis of prostate cancer.

The present study is, to our knowledge, the largest study issued to explore the relation between height/BMI and prostate cancer, allowing a more detailed categorisation than in previous studies. The largest study so far on the association between BMI and prostate cancer (Rodriguez et al, 2001) included 820000 men. The data were from the American Cancer Prevention Study I and II

Table 3 Relative risk (RR) of prostate cancer from the Cox regression analysis with 95\% confidence intervals (Cl) by age at measurement and body mass index (BMI) or height, adjusted for birth cohort

Age at measurement (years)

\begin{tabular}{|c|c|c|c|c|c|c|c|c|c|c|c|c|}
\hline Var & \multicolumn{2}{|c|}{$20-29$ (622 cases) } & \multicolumn{2}{|c|}{$30-39$ (3196 cases) } & \multicolumn{2}{|c|}{ 40-49 (8996 cases) } & \multicolumn{2}{|c|}{$50-59$ ( 11009 cases $)$} & \multicolumn{2}{|c|}{ 60-69 (7594 cases) } & \multicolumn{2}{|c|}{$70-74$ (1897 cases) } \\
\hline \multicolumn{13}{|l|}{$\mathrm{BMI}\left(\mathrm{kg} \mathrm{m}^{-2}\right)$} \\
\hline $18.50-24.99$ & 1.00 & Referent & 1.00 & Referent & 1.00 & Referent & 1.00 & Referent & 1.00 & Referent & 1.00 & Referent \\
\hline $25.00-29.99$ & 1.20 & $1.00-1.44$ & 1.06 & $0.99-1.14$ & 1.06 & $1.02-1.11$ & 1.09 & $1.05-1.14$ & 1.08 & $1.03-1.13$ & 1.08 & $0.98-1.18$ \\
\hline$\geqslant 30.00$ & 1.22 & $0.69-2.17$ & 1.19 & $0.99-1.44$ & 1.05 & $0.95-1.16$ & 1.05 & $0.97-1.14$ & 1.14 & $1.04-1.24$ & 1.04 & $0.87-1.23$ \\
\hline $170-179$ & 1.00 & Referent & 1.00 & Referent & 1.00 & Referent & 1.00 & Referent & 1.00 & Referent & 1.00 & Referent \\
\hline $180-189$ & 1.14 & $0.97-1.35$ & 1.04 & $0.96-1.12$ & 1.04 & $0.99-1.09$ & 1.02 & $0.97-1.08$ & 1.10 & $1.02-1.19$ & 1.16 & $0.97-1.37$ \\
\hline$\geqslant 190$ & 0.62 & $0.34-1.13$ & 1.12 & $0.89-1.42$ & 1.18 & $1.00-1.40$ & 1.08 & $0.85-1.38$ & 1.00 & $0.64-1.58$ & 0.00 & $0.00-\infty$ \\
\hline
\end{tabular}


Table 4 Relative risk (RR) of prostate cancer from the Cox regression analysis with 95\% confidence intervals (Cl) by attained age and body mass index (BMI) or height, adjusted for birth cohort and age at measurement ${ }^{\mathrm{a}}$

\begin{tabular}{|c|c|c|c|c|c|c|c|c|}
\hline \multirow[b]{3}{*}{ Variable } & \multicolumn{8}{|c|}{ Attained age (years) } \\
\hline & \multicolumn{2}{|c|}{$50-59$ ( 1813 cases) } & \multicolumn{2}{|c|}{ 60-69 (95 I I cases) } & \multicolumn{2}{|c|}{$70-79$ ( 15429 cases) } & \multicolumn{2}{|c|}{$80-99$ (6432 cases) } \\
\hline & $\mathbf{R R}$ & $95 \% \mathrm{Cl}$ & $\mathbf{R R}$ & $95 \% \mathrm{Cl}$ & $\mathbf{R R}$ & $95 \% \mathrm{Cl}$ & $\mathbf{R R}$ & $95 \% \mathrm{Cl}$ \\
\hline \multicolumn{9}{|l|}{ BMI $\left(\mathrm{kg} \mathrm{m}^{-2}\right)$} \\
\hline$<18.50$ & 0.82 & $0.41-1.65$ & 0.89 & $0.65-1.22$ & 0.80 & $0.62-1.02$ & 1.05 & $0.76-1.47$ \\
\hline $18.50-24.99$ & 1.00 & Referent & 1.00 & Referent & 1.00 & Referent & 1.00 & Referent \\
\hline $25.00-29.99$ & 1.13 & $1.02-1.25$ & 1.04 & $1.00-1.09$ & 1.07 & $|.04-1.1|$ & 1.07 & $1.02-1.13$ \\
\hline$<160$ & 0.45 & $0.17-1.19$ & 0.45 & $0.32-0.64$ & 0.70 & $0.59-0.82$ & 0.63 & $0.50-0.79$ \\
\hline $160-169$ & 0.83 & $0.72-0.97$ & 0.88 & $0.83-0.93$ & 0.92 & $0.89-0.96$ & 0.84 & $0.80-0.89$ \\
\hline $170-179$ & 1.00 & Referent & 1.00 & Referent & 1.00 & Referent & 1.00 & Referent \\
\hline $180-189$ & 1.03 & $0.92-1.14$ & 1.09 & $1.04-1.15$ & 1.07 & $1.02-1.11$ & 1.02 & $0.95-1.11$ \\
\hline$\geqslant 190$ & 0.85 & $0.60-1.21$ & 1.33 & $1.13-1.56$ & 1.01 & $0.83-1.24$ & 1.03 & $0.66-1.60$ \\
\hline
\end{tabular}

${ }^{a}$ Mean age at measurement (minimum-maximum) in the different strata: 50-59: 41 years (20-60); 60-69: 49 years (22-70); 70-79: 55 years (32-75); 80-99: 60 years $(42-75)$.

(CPS-I and CPS-II), and included 5200 prostate cancer deaths. A Swedish study (Andersson et al, 1997) included 2400 incident cases of prostate cancer and 700 deaths from prostate cancer. The present study included 33300 incident cases.

The large study size made it possible to perform a number of stratified analyses, with high statistical power, which has not been possible in other studies on this issue. However, the stratified analyses were performed without having any specific hypothesis in advance. Therefore, the results must be interpreted with caution. The findings may be chance findings.

A stratified analysis by attained age revealed that there was a marked increased risk of prostate cancer in obese men compared with normal weighted men at age 50-59 years, while the RR in older age groups were modest. Since the incidence of prostate cancer is much higher at older ages, this effect, if it is real, will be hidden in studies where much of the total observation time is above this age. This might explain some of the inconsistencies between previous studies. In a recent review (Nomura, 2001), two of 10 cohort studies revealed a positive association between BMI and prostate cancer. These two studies (Andersson et al, 1997; Veierød et al, 1997) included relatively young populations. In one study (Veierød et al, 1997), using a subcohort of the present study $(<3 \%$ of the men, $<2 \%$ of the person-years), $91 \%$ of the person-years and $42 \%$ of the cases were less than 60 years. In the other study (Andersson et al, 1997), the association between BMI and both incidence of and mortality from prostate cancer was studied in a cohort of 135000 Swedish construction workers followed for an average of 18 years; $53 \%$ of the men were below age 60 years during the entire follow-up period and additional 19\% were below 60 years in most of the follow-up period. The association between BMI and prostate cancer was stronger when looking at mortality than at incidence. The study by Rodriguez et al (2001), not being included in the review by Nomura, found a positive association between BMI and prostate cancer mortality in both study cohorts. In CPS-I and CPS-II, the men had median age of between 52 and 57 years, respectively. The average follow-up was 12 years. In another study (Thune and Lund, 1994), not included in the review by Nomura, an increased risk of prostate cancer by increasing BMI in a cohort using parts of the present study cohort ( $<5 \%$ of the men, $<3 \%$ of the person-years) was found. Also in this cohort, the men were relatively young with a median age at prostate cancer diagnosis of 61 years.

The four largest cohort studies reviewed by Nomura (2001), which did not find an association between BMI and prostate cancer, seemed to include a larger proportion of person-years above the age of 60 years than in the studies that found positive associations. In a Dutch study (Schuurman et al, 2000), 55-69year-old men were followed for an average of 6 years. The median age at diagnosis was 70 years in the study by Habel et al (2000). Giovannucci et al (1997) followed 40-75-year-old men for an average of 7 years. A Norwegian study (Nilsen and Vatten, 1999), using a subcohort of the present study ( $2 \%$ of the men, $1 \%$ of the person-years), included men with a mean age of 59 years at the start of follow-up.

The majority of prostate cancer cases occur in men above the age of 60 years. However, the relative increase in prostate cancer incidence is higher in men aged 50-59 years than in other age groups both in the US as well as in other countries (Hsing et al, 2000 ). This can be both due to differences in screening practices by age, and the increasing proportion of obese men, suggested by an increased risk due to obesity in this age group in the present study.

Use of the Cox proportional hazards regression models assumes that RRs do not vary by time. The present finding of a somewhat different impact of obesity on the risk of prostate cancer at age $50-$ 59 years violates the proportionality assumption in the Cox model. Restricting the analysis to ages above 60 years gave similar results as the main analysis, due to the low number of prostate cancer cases under the age of 60 years.

Some of the strengths of the present study were that height and weight were measured in various ages over a wide age-span and the long follow-up. Hence, we could adjust for age at measurement in the analyses. However, men being 80-99 years during the followup period had an average age at measurement of 60 years and only $11 \%$ were less than 50 years old. A possible explanation for a decreasing RR by attained age is that certain levels of BMI may have different meaning in young age and older age. However, persons with a BMI above 30 generally have a high percentage of fat, irrespective of age.

Some studies have looked at mortality from prostate cancer instead of incidence (Andersson et al, 1997; Rodriguez et al, 2001). Decreased survival among obese men has been suggested as an explanation for the stronger association between BMI and prostate cancer mortality (Rodriguez et al, 2001). Previous studies of the impact of BMI on the incidence of prostate cancer have been inconsistent, while studies on prostate cancer mortality have more consistently shown increased risk associated with obesity (Rodriguez et al, 2001). In the present study, we studied cancer incidence with the inclusion of histologically verified prostate cancers only. 
The results of the present study on the relation between BMI and risk of prostate cancer were consistent with the estimates given by Bergström et al (2001). Use of the same intervals of BMI $(\mathrm{BMI}<20.0,20.0-24.9,25.0-29.9$, and $\geqslant 30.0)$ as Bergström et al, gave RRs of 1.07 (95\% CI: 1.04-1.09) for men with BMI 25-29 and 1.09 (95\% CI: $1.04-1.14$ ) for men with BMI above $30 \mathrm{~kg} \mathrm{~m}^{-2}$ compared with those having BMI $20-24 \mathrm{~kg} \mathrm{~m}^{-2}$.

Even though only two of the nine cohort studies included in the review by Nomura (2001) found a significant positive association between height and prostate cancer, seven of the eight studies with an RR for height had RRs above one. Four (Andersson et al, 1997; Veierød et al, 1997; Nilsen and Vatten, 1999; Habel et al, 2000) of the six largest studies (Andersson et al, 1997; Giovannucci et al, 1997; Veierød et al, 1997; Nilsen and Vatten, 1999; Habel et al, 2000; Schuurman et al, 2000) found a 10-20\% higher risk of prostate cancer in the highest quintile or quartile compared with the lowest. One study (Giovannucci et al, 1997) found an RR of 1.4 in the highest category compared with the lowest, while one study did not find any association at all (Schuurman et al, 2000). More recently, a positive association has been observed in CPS-I, but not in CPS-II (Rodriguez et al, 2001). In the present study, a markedly increased risk was found in the highest compared with the lowest men. The low risk connected to the shortest men can partly be explained by low incidence in the shortest men in the two northernmost counties in Norway. These two counties have a relatively large proportion of Lapps, who are generally short and have a low incidence of prostate cancer (Baste et al, 1992; Harvei, 1999). Categorising height by quintiles instead of the first chosen categorisation gave an RR of 1.20 (95\% CI: $1.16-1.25)$ when comparing the highest with the lowest quintile. Excluding the two northernmost counties gave a slightly lower $R R(R R=1.17 ; 95 \%$ CI: $1.13-1.21)$. The biological mechanisms underlying a possible association between height and prostate cancer are uncertain (Gunnell et al, 2001). A possible explanation is that height acts as a marker for the levels of insulin-like growth factors (IGFs) (Gunnell et al, 2001). An increased risk of prostate cancer has been observed in men with elevated plasma insulin-like growth factor-I (IGF-I) (Chan et al, 1998; Stattin et al, 2000).

In summary, in this large Norwegian cohort both height and BMI were positively associated with the risk of prostate cancer. The overall magnitude of the increase in risk of prostate cancer by increasing BMI was modest. However, in the age group 50-59 years, obese men had 58\% higher risk than normal weighted men. The larger effect in this age group might partially explain the previous inconsistent findings. Even though the overall increased prostate cancer risk by BMI is minor, the large incidence of prostate cancer in older men in combination with the increasing BMI in many Western populations will increase the future importance of BMI as a risk factor for prostate cancer.

\section{ACKNOWLEDGEMENTS}

We are grateful to those who, during almost 40 years, collected the data used in the present study. These are persons connected to the former National Health Screening Service, The Nord-Trøndelag health survey (HUNT), The Hordaland health survey (HUSK), and The Troms $\varnothing$ study.

\section{REFERENCES}

Andersson SO, Wolk A, Bergström R, Adami HO, Engholm G, Nyrén O (1997) Body size and prostate cancer: a 20-year follow-up study among 135006 Swedish construction workers. J Natl Cancer Inst 89: $385-389$

Baste V, Bjørge T, Lund KE, Andersen A (1992) Cancer incidence in areas with different proportion of Lapps. A report from the Nordic summerschool in cancer epidemiology in 1991. Oslo, The Cancer Registry of Norway

Bergström A, Pisani P, Tenet V, Wolk A, Adami HO (2001) Overweight as an avoidable cause of cancer in Europe. Int J Cancer 91: 421-430

Bianchini F, Kaaks R, Vainio H (2002) Overweight, obesity, and cancer risk. Lancet Oncol 3: $565-574$

Bjartveit K (1997) (The National Health Screening Service: From fight against tuberculosis to many-sided epidemiological activities) Fra tuberkulosekamp til mangesidig epidemiologisk virksomhet. Nor Epidemiol 7: $157-174$

Bjartveit K, Foss OP, Gjervig T, Lund-Larsen PG (1979) The cardiovascular disease study in Norwegian counties. Background and organization. Acta Med Scand Suppl 634: 1-70

Chan JM, Stampfer MJ, Giovannucci E, Gann PH, Ma J, Wilkinson P, Hennekens CH, Pollak M (1998) Plasma insulin-like growth factor-I and prostate cancer risk: a prospective study. Science 279: 563-566

Cox DR, Oakes D (1984) Analysis of Survival Data. London: Chapman and Hall Ltd

Engeland A, Bjørge T, Selmer RM, Tverdal A (2003) Height and body mass index in relation to total mortality. Epidemiology 14: $293-299$

Giovannucci E, Rimm EB, Stampfer MJ, Colditz GA, Willett WC (1997) Height, body weight, and risk of prostate cancer. Cancer Epidemiol Biomarkers Prev 6: 557-563

Gunnell D, Okasha M, Davey Smith G, Oliver SE, Sandhu J, Holly JM (2001) Height, leg length, and cancer risk: a systematic review. Epidemiol Rev 23: $313-342$

Habel LA, Van Den Eeden SK, Friedman GD (2000) Body size, age at shaving initiation, and prostate cancer in a large, multiracial cohort. Prostate 43: $136-143$
Harvei S (1999) The epidemiology of prostatic cancer. Tidsskr Nor Laegeforen 119: 3589-3594

Harvei S, Tretli S, Langmark F (1996) Quality of prostate cancer data in the cancer registry of Norway. Eur J Cancer 32A: $104-110$

Helseth A, Tretli S (1989) Pre-morbid height and weight as risk factors for development of central nervous system neoplasms. Neuroepidemiology 8: $277-282$

Hsing AW, Chang L, Nomura AM, Isaacs WB, Armenian HK (2001) A glimpse into the future. Epidemiol Rev 23: 2

Hsing AW, Tsao L, Devesa SS (2000) International trends and patterns of prostate cancer incidence and mortality. Int J Cancer 85: $60-67$

Nilsen TI, Vatten LJ (1999) Anthropometry and prostate cancer risk: a prospective study of 22,248 Norwegian men. Cancer Causes Control 10: $269-275$

Nomura AM (2001) Body size and prostate cancer. Epidemiol Rev 23: $126-131$

Parkin DM, Bray FI, Devesa SS (2001) Cancer burden in the year 2000. The global picture. Eur J Cancer 37 (Suppl 8): S4-S66

Robsahm TE, Tretli S (1999) Height, weight and gastrointestinal cancer: a follow-up study in Norway. Eur J Cancer Prev 8: $105-113$

Rodriguez C, Patel AV, Calle EE, Jacobs EJ, Chao A, Thun MJ (2001) Body mass index, height, and prostate cancer mortality in two large cohorts of adult men in the United States. Cancer Epidemiol Biomarkers Prev 10: $345-353$

Schuurman AG, Goldbohm RA, Dorant E, van den Brandt PA (2000) Anthropometry in relation to prostate cancer risk in the Netherlands Cohort Study. Am J Epidemiol 151: 541-549

SPSS Inc. (2001) SPSS for Windows. Release 11.0.1. 15-11-2001

Stattin P, Bylund A, Rinaldi S, Biessy C, Déchaud H, Stenman UH, Egevad L, Riboli E, Hallmans G, Kaaks R (2000) Plasma insulin-like growth factor-I, insulin-like growth factor-binding proteins, and prostate cancer risk: a prospective study. J Natl Cancer Inst 92: $1910-1917$ 
Thune I, Lund E (1994) Physical activity and the risk of prostate and testicular cancer: a cohort study of 53,000 Norwegian men. Cancer Causes Control 5: 549-556

Thune I, Olsen A, Albrektsen G, Tretli S (1993) Cutaneous malignant melanoma: association with height, weight and body-surface area. A prospective study in Norway. Int J Cancer 55: 555-561

Tretli S (1989) Height and weight in relation to breast cancer morbidity and mortality A prospective study of 570,000 women in Norway. Int J Cancer 44: $23-30$

Tretli S, Magnus K (1990) Height and weight in relation to uterine corpus cancer morbidity and mortality. A follow-up study of 570,000 women in Norway. Int J Cancer 46: 165-172
Tretli S, Robsahm TE (1999) Height, weight and cancer of the oesophagus and stomach: a follow-up study in Norway. Eur J Cancer Prev 8: $115-122$

Veierød MB, Laake P, Thelle DS (1997) Dietary fat intake and risk of prostate cancer: a prospective study of 25,708 Norwegian men. Int $J$ Cancer 73: $634-638$

Waaler HT (1984) Height, weight and mortality. The Norwegian experiment. Acta Med Scand Supplement 679: 1-56

World Health Organization Consultation on Obesity (1998) Preventing and managing the global epidemic: report of a WHO Consultation on Obesity, pp. 1-276. Geneva, 3 - 5 June 1997. Geneva, Switzerland: World Health Organization 